\title{
SoIl MoIsture and TeMPERATURE CHARACTERISTICS IN A Young SilvoARABLE Agroforestry SySTEM
}

\author{
Nóra SZigeti, Andrea ViTYI \\ University of Sopron, Institute of Forest and Environmental Techniques \\ H-9400 Sopron, Bajcsy-Zs. u. 4.
}

\begin{abstract}
The aim of the present research is to investigate the effect of a young alley cropping system (planted for experimental purposes) on the soil microclimate, compared with a control site. The trial system, involving the agroforestry plantation and a control site, has been implemented in 2013 in an intensive monoculture agricultural environment. Measurement of soil microclimatic parameters started in 2014. Based on the results of the examination carried out in an agroforestry and a monoculture production site, there is a clear difference between soil moisture and soil temperature of the two cultivation systems. This effect can be observed even from the second year of the fast growing tree (Paulownia) plantation.
\end{abstract}

Keywords: agroforestry, alley cropping, soil moisture

\section{INTRODUCTION}

Intensive agricultural land use has a complex negative impact on soil, involving contamination, decreasing biological activity, fertility loss, etc. (Li et al., 2019; KrautCohen et al., 2019; Baysal and Saygin, 2018). In addition, more and more frequent occurrences of weather extremes, such as drought and water floods, have a negative effect on natural vegetation and the qualitative and quantitative parameters of agricultural production as well as its ecological sustainability (Johansson et al., 2015). Agroecological systems can prove the opportunity to maintain productivity and in a sustainable form (Ball et al., 2018). One promising aspect of adapting to climate change is agroforestry, which integrates woody vegetation into agricultural cultivation, exploiting its various economic, social and ecological benefits. Cherubin et al. (2019) found that agroforestry improves the physical quality of the soil, taking into account the characteristics of soil aggregate and biological activity in degraded lands.

In our research we measured soil microclimate parameters in a trial agroforestry and a control site to investigate the effect of the tree grows in their first years in an intensively cultivated agricultural area.

\section{MATERIALS AND METHODS}

The trial alley cropping plantation has been implemented in 2013 in an intensively cultivated environment in South Hungary. The control site is a monocrop field next 
to the agroforestry system. A comparative test of soil parameters proved, that the main characteristics (alkaline clay / clayey loam type slightly solonchak soil) of the researched habitats are the same. On the alley cropping site, 126 pieces of Paulownia tomentosa var. Continental E. tree saplings have been planted on a 1 ha area. The distance between the rows and trees is $14 \mathrm{~m}$ and $5 \mathrm{~m}$, respectively. The alleys are intercropped with alfalfa. The control site, with the same size is an alfalfa monocrop plantation. This study is based on the soil moisture and temperature data collected from 2013 to 2017, at four different depths: 0-10 cm, 10-20 cm, 20-40 cm and 40-60 $\mathrm{cm}$ by installed tensiometers and soil thermometers. Air temperature was also measured in the trial site. The sensors have been installed so that the intercrop, the tree rows, and also control areas are monitored (Figure 1). Data have been collected automatically for four years, in two hours' interval. For ease of use, the analysis is based on the daily averages, calculated from the data series in the growing seasons (1. April to 30. September) of the four years. The annual changes in soil moisture and temperature values are shown in box diagrams, which also indicate the deviation of data. In the arid periods, which the agricultural cultivation is particularly sensitive to, the typical processes are well illustrated by the curves of daily averages compared to the air temperature, rain amount and wind speed. Statements based on the diagrams have been controlled and supported by statistical t-tests.

\section{Figure 1}

\section{Installation of the sensors to monitor the intercrop, the tree rows and the control areas.}

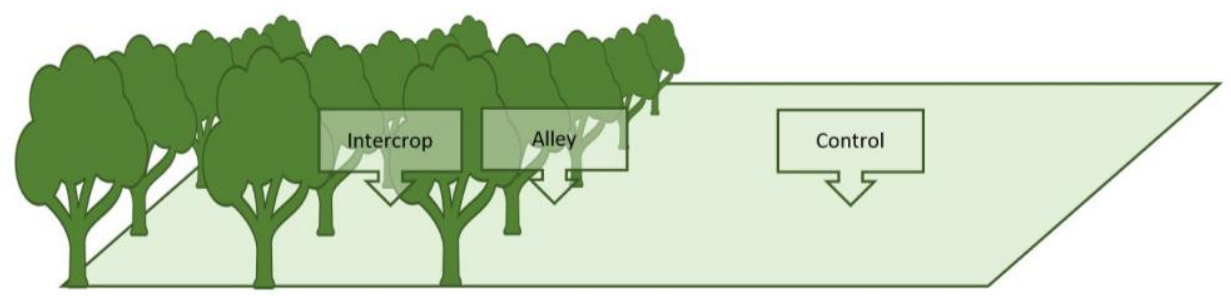

\section{RESULTS AND DISCUSSION}

According to soil moisture, in the control site, the upper layer of soil - up to 20 $\mathrm{cm}$ depth -, was significantly drier than in the alleys and intercrop plots. More frequent and higher soil dryness could be observed in monoculture production, while the majority of the data collected in the agroforestry system was located in a more favourable range, the total dehydration appeared only occasionally (Figure 2). Soil dryness refers to water potential values above $100 \mathrm{~cm}$, where water scarcity is already threatening to achieve maximum yield.

In the deeper soil layers $(>20 \mathrm{~cm})$ this tendency is not so clear; in the last examined growing season the soil moisture of the control area was more favourable (Figure 3). In this depth, soil moisture could be affected by the (partial) aquitard layer in $30 \mathrm{~cm}$ depth, the deep roots of trees and alfalfa, and the availability of ground water. 
Figure 2

Soil moisture in 0-20 $\mathrm{cm}$ depth

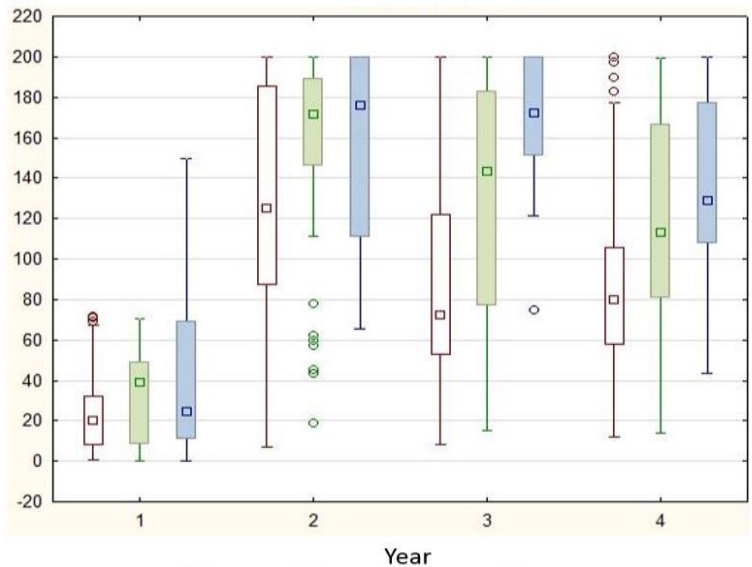

Legend: $\square$ Alley $\square$ Intercrop $\square$ Control

The water potency of the soil moisture measured by tensiometer (water shortage) expressed in centibar in the upper soil layers in the four growing seasons

\section{Figure 3}

\section{Soil moisture in 20-60 cm depth}

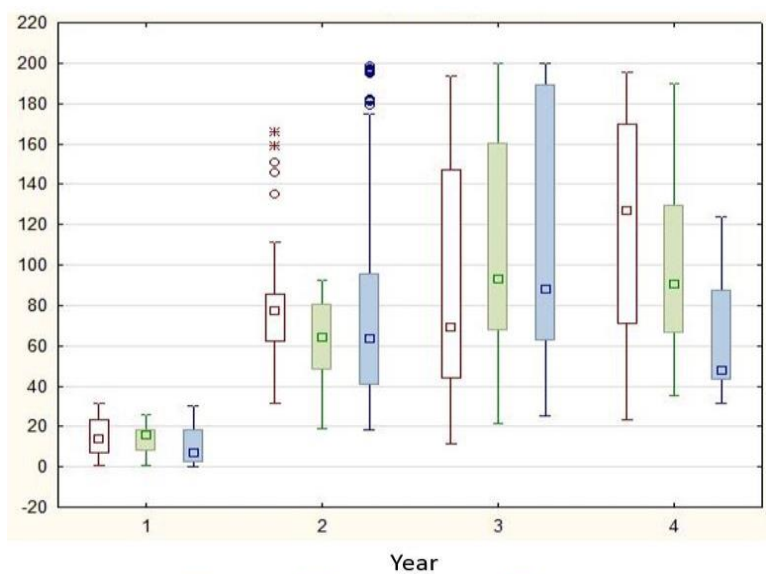

Legend: 回 Alley Intercrop $\square$ Control

The water potency of the soil moisture measured by tensiometer (water shortage) expressed in centibar in the deeper soil layers in the four growing seasons

According to the data, the presence of trees in the arable cultivation has a favourable effect on the water content of upper soil layers already in the first years, 
by reducing the drying effect of wind and direct sunlight. During arid periods, dehydration occurred later in agroforestry site and took shorter periods in the upper soil layers than in the control plot. In the deeper soil layers (below $20 \mathrm{~cm}$ ) the difference in soil moisture values of the agroforestry and control plots was smaller during the same drought period (Figure 4).

\section{Figure 4}

\section{Soil moisture in a drought period}
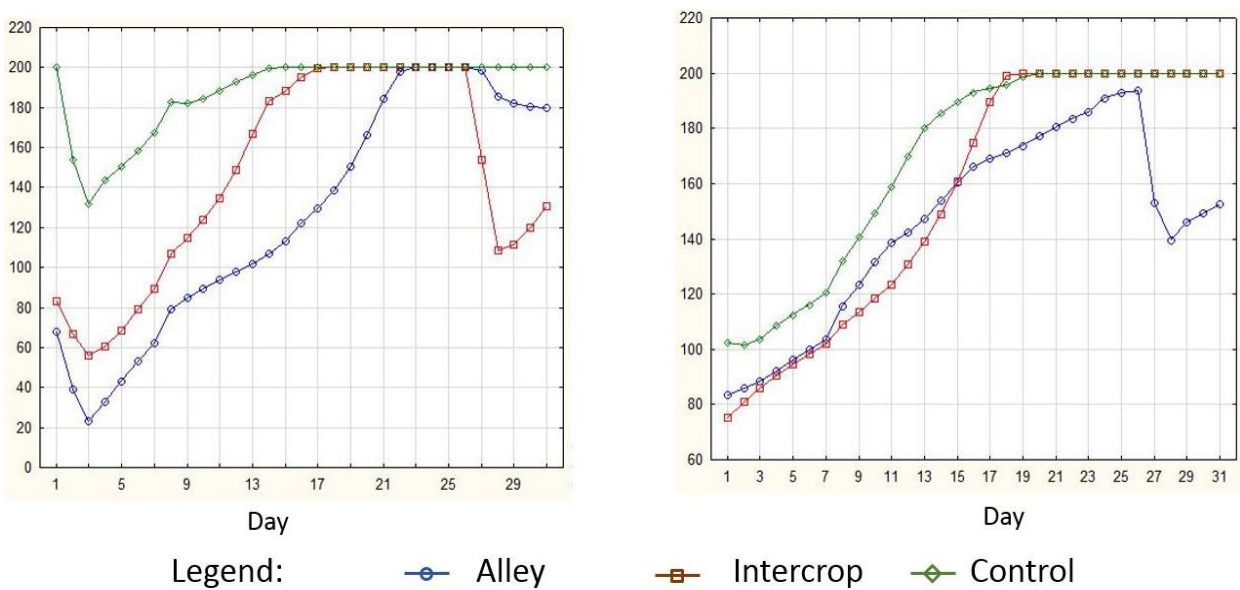

The water potency of the soil moisture measured by tensiometer (water shortage) expressed in centibar in the upper $(0-20 \mathrm{~cm}$, left) and deeper $(>20 \mathrm{~cm}$, right) soil layers during a drought period 21.08.2016 23.09.2016. The soil moisture values measured with the tensiometer indicate the absorption capacity of the soil, so higher values mean drier soil conditions.

Examining the soil temperature data, we can state that the deviation in the control site was higher than in the agroforestry system in all four examined soil layers, but most at the upper measuring points. The annual average of the values and the majority of the data collected in the agroforestry site were in a more favourable range for productivity than in the monoculture (Figure 5 and Figure 6).

In the drought periods, while the temperature of the upper - up to $20 \mathrm{~cm}$ depth soil layer of the sites followed the changes of air temperature, the soil in the agroforestry system had a milder degree of warming on the one hand, and was considerably more temperate on the other hand. Although to a smaller extent, but this phenomenon could be observed even in layers up to $60 \mathrm{~cm}$ depth (Figure 7).

Contrary to our experience, several examples can be found in international literature, where tree rows have a neutral or negative effect on the intermediate crop. Ssekabembe et al. (1994) indicate the importance of soil type when determining soil moisture in a black locust alley cropping system. According to tree-crop competition, Swieter et al. (2018) found that the average, long term crop yield of oilseed rape and 
winter wheat did not differ significantly in a 10 year old alley cropping and monoculture system.

\section{Figure 5}

\section{Soil temperature in $0-20 \mathrm{~cm}$ depth}

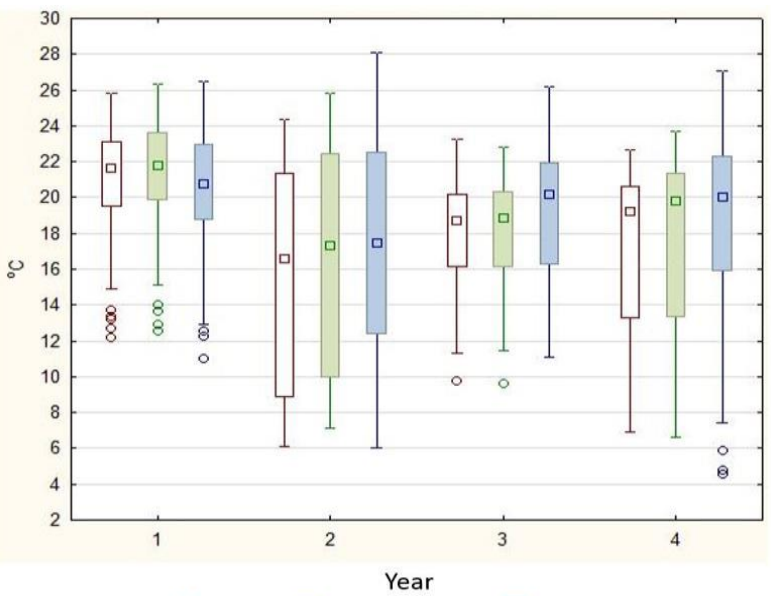

Legend: $\square$ Alley $\square$ Intercrop $\square$ Control

Soil temperature values in the upper $(0-20 \mathrm{~cm})$ soil layers during the four examined growing periods

\section{Figure 6}

Soil temperature in $20-60 \mathrm{~cm}$ depth

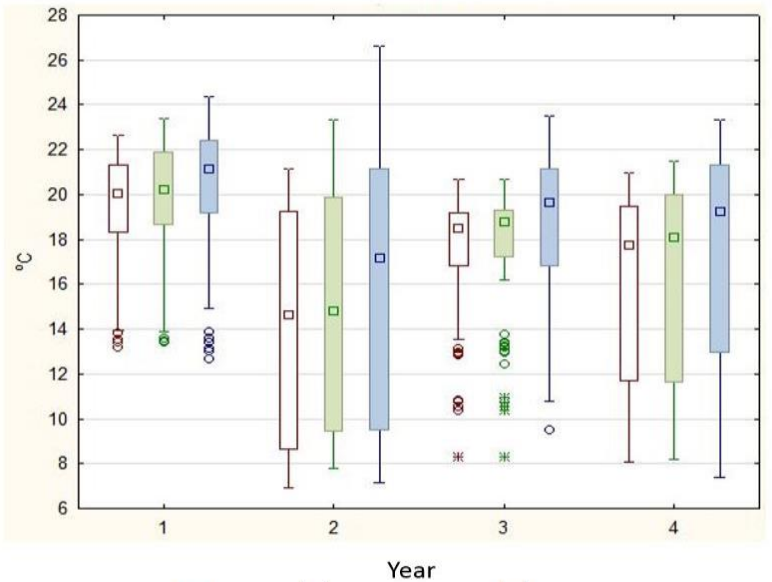

Legend: 0 Alley $\square$ Intercrop $\square$ Control

Soil temperature values in the deeper $(>20 \mathrm{~cm})$ soil layers during the four examined growing periods 


\section{Figure 7}

\section{Soil temperature in a drought period}
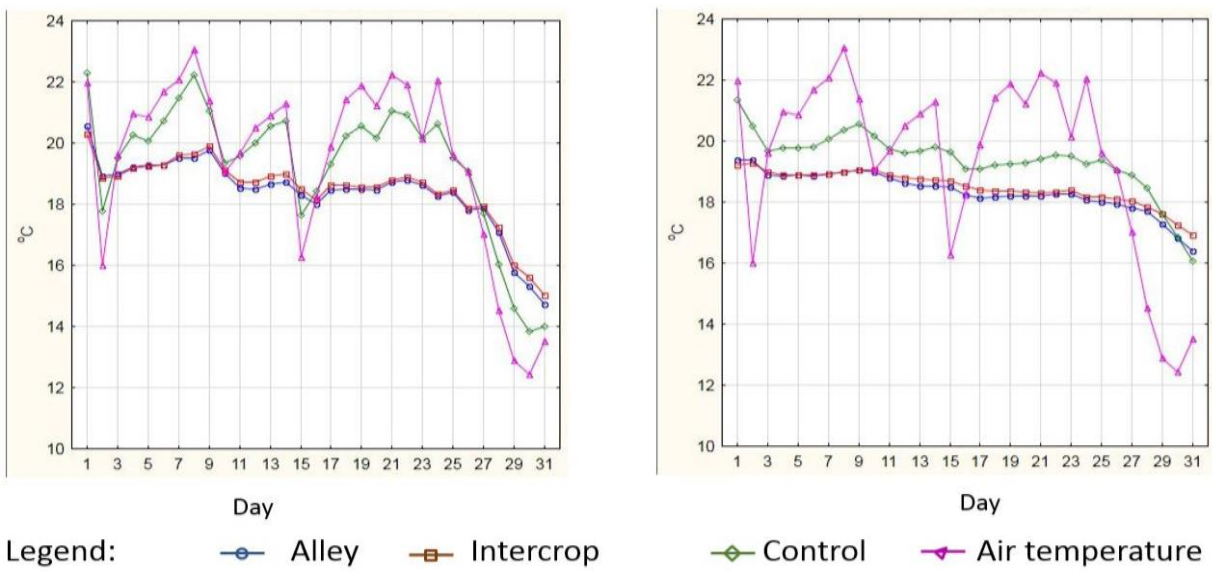

Soil temperature values in the upper $(0-20 \mathrm{~cm}$, left) and deeper $(>20 \mathrm{~cm}$, right) soil layers in a drought period 21.08.2016 23.09.2016.

Besides the soil types, the tree species also can negatively affect the production in alley cropping, as highlighted by Malik and Sharma (1990). On the other hand, intercrop can also support the growth of tree alleys, as it is highlighted in several publications (Williams and Gordon, 1995; Vityi et al., 2016).

\section{CONCLUSIONS}

Based on the results of the examination carried out in an agroforestry and a monoculture production site, there is a clear difference between soil moisture and soil temperature of the two cultivation systems. This effect can be observed even from the second year of the fast growing tree (Paulownia) plantation.

Woody vegetation helped to preserve soil moisture in the upper $20-30 \mathrm{~cm}$ layer, but caused a decrease in layers below $30 \mathrm{~cm}$ (under aquitard layer). The presence of trees is beneficial for the soil temperature; the soil microclimate is more balanced in the agroforestry system than in monoculture due to the decrease of the mean values in the upper layers, the smaller deviance of data and the less frequent prevalence of extreme values of temperature.

Overall, based on the results of the experiment, the alley cropping system can be particularly favourable for shallow-rooted intercrops, by controlling the water and heat balance of the soil and by moderating harmful extremities such as drought, extreme cold or heat.

\section{AKNOWLEDGEMENT}

The publication of this paper is supported by the EFOP-3.6.2-16-2017-00018 "Produce together with the nature - agroforestry as a new outbreaking possibility" project. 


\section{REFERENCES}

Ball, B.C., Hargreaves, P.R., Watson, C.A. (2018) A framework of connections between soil and people can help improve sustainability of the food system and soil functions. In: Ambio, 47. 3. 269-283. p. doi: 10.1007/s13280-017-0965-z

Baysal, A., Sayg1n, H. (2018) Effect of zinc oxide nanoparticles on the trace element contents of soils. In: Chemistry and Ecology, 34. 8. 713-726. p. doi: 10.1080/02757540.2018.1491556

Cherubin, M.R., Chavarro-Bermeo, J.P., Silva-Olaya, A.M. (2019) Agroforestry systems improve soil physical quality in northwestern Colombian Amazon. In: Agroforestry Systems 93. 1741-1753 p. doi: 10.1007/s10457-018-0282-y

Johansson, R., Luebehusen, E., Morris, B., Shannon, H., Meyer, S. (2015): Monitoring the impacts of weather and climate extremes on global agricultural production. In: Weather and Climate Extremes 10. 65-71. p. doi: 10.1016/j.wace.2015.11.003

Kraut-Cohen, J., Zolti, A., Shaltiel-Harpaz, L. Argaman, E., Rabinovich, R., Green, S.J., Minz, D. (2019): Effects of tillage practices on soil microbiome and agricultural parameters. In: Science of the Total Environment (2019), doi: 10.1016/j.scitotenv.2019.135791

Li, X., Zhang, J., Gong, Y., Liu, Q., Yang, S., Ma, J., Zhao, L., Hou, H. (2019) Status of copper accumulation in agricultural soils across China (1985-2016). In: Chemosphere, 244. 125516. p. doi: 10.1016/j.chemosphere.2019.125516

Malik, R.S., Sharma, S.K. (1990): Moisture extraction and crop yield as a function of distance from a row of Eucalyptus tereticornis. In: Agroforestry Systems, 12. 2. 187-195. p. doi: 10.1007/BF00123473

Ssekabembe, CK., Henderlong, PR., Larson, M. (1994) Soil moisture relations at the tree/crop interface in black locust alleys. In: Agroforestry Systems 25. 2. 135140. p. doi: $10.1007 / \mathrm{BF} 00705673$

Swieter, A., Langhof, M., Lamerre, M., Greef, JM. (2018) Long-term yields of oilseed rape and winter wheat in a short rotation alley cropping agroforestry system Agroforestry System, 93. 5. 1853-1864. p. doi: 10.1007/s10457-018-0288-5

Williams, P.A., Gordon, A.M. (1995) Microclimate and soil moisture effects of three intercrops on the rows of a newly-planted intercropped plantation. In: Agroforestry Systems 29. 3. 285-302. p. doi: $10.1007 /$ BF00704875

Corresponding author:

\section{Nóra SZIGETI}

University of Sopron

Institute of Forest and Environmental Techniques

H-9400 Sopron, Bajcsy-Zs. u. 4.

phone: +3699518-919

e-mail: szigeti.nora@uni-sopron.hu 